Journal of Cellular Biochemistry 101:676-685 (2007)

\title{
CCR2 Expression Correlates With Prostate Cancer Progression
}

\author{
Yi Lu, ${ }^{1,2}$ Zhong Cai, ${ }^{1,3}$ Guozhi Xiao, ${ }^{1}$ Yulin Liu, ${ }^{4}$ Evan T. Keller, ${ }^{5}$ Zhi Yao, ${ }^{2}$ and Jian Zhang ${ }^{1 *}$ \\ ${ }^{1}$ Department of Medicine, University of Pittsburgh, Pittsburgh, PA 15240 \\ ${ }^{2}$ Department of Immunology, Tianjin Medical University, Tianjin, China \\ ${ }^{3}$ Department of Clinical Chemistry, Tianjin Chest Hospital, Tianjin, China \\ ${ }^{4}$ Department of Pathology, Allegheny General Hospital, Pittsburgh, PA 15212 \\ ${ }^{5}$ Department of Urology, University of Michigan, Ann Arbor, MI 48109
}

\begin{abstract}
Although the primary role of chemokines and their receptors is controlling the trafficking of leukocytes during inflammatory responses, they also play pleoitropic roles in cancer development. There is emerging evidence that cancer cells produce chemokines that induce tumor cell proliferation or chemotaxis in various cancer types. We have previously reported that MCP-1 acts as a paracrine and autocrine factor for prostate cancer (PCa) growth and invasion. As the cellular effects of MCP-1 are mediated by CC chemokine receptor 2 (CCR2), we hypothesized that CCR2 may contribute PCa progression. Accordingly, we first determined CCR2 mRNA and protein expression in various cancer cell lines, including PCa and other cancer types. All cells expressed CCR2 mRNA and protein, but in PCa, more aggressive cancer cells such as C4-2B, DU145, and PC3 expressed a higher amount of CCR2 compared with the less aggressive cancer cells such as LNCaP or non-neoplastic PrEC and RWPE-1 cells. Further, we found a positive correlation between CCR2 expression and PCa progression by analyzing an ONCOMINE gene array database. We confirmed that CCR2 mRNA was highly expressed in PCa metastatic tissues compared with the localized PCa or benign prostate tissues by realtime RT-PCR. Finally, CCR2 protein expression was examined by immunohistochemical staining on tissue microarray specimens from 96 PCa patients and 31 benign tissue controls. We found that CCR2 expression correlated with Gleason score and clinical pathologic stages, whereas lower levels of CCR2 were expressed in normal prostate tissues. These results suggest that CCR2 may contribute to PCa development. J. Cell. Biochem. 101: 676-685, 2007. ๑ 2007 Wiley-Liss, Inc.
\end{abstract}

Key words: CCR2; monocyte chemotactic protein-1; prostate cancer; metastasis

Bone is the most frequent site for distant metastasis from prostate cancer (PCa). It was reported that skeletal metastases occurred in up to $90 \%$ of patients dying from $\mathrm{PCa}$ [Abrams et al., 1950; Rana et al., 1993; Landis et al., 1999; Bubendorf et al., 2000]. Skeletal metastases cause significant complications including

Grant sponsor: National Cancer Institute Specialized Programs of Research Excellence; Grant number: 1 P50 CA 69568; Grant sponsor: University of Pittsburgh Internal Support.

*Correspondence to: Jian Zhang, Department of Medicine, Room 2E110, Pittsburgh VA Healthcare System, Research \& Development (151C-U), University Drive, University of Pittsburgh, Pittsburgh, PA 15240.

E-mail: zhangj2@upmc.edu

Received 12 September 2006; Accepted 2 November 2006

DOI 10.1002/jcb.21220

(c) 2007 Wiley-Liss, Inc. severe bone pain, impaired mobility, pathological fracture, spinal cord compression, and hypercalcemia [Coleman, 1997; Moul and Lipo, 1999]. Despite advances in management of $\mathrm{PCa}$, skeletal metastases remain incurable. Strategies to inhibit PCa metastasis include targeting the dynamic and bidirectional interactions between tumor cells and the bone microenvironments. The bone microenvironment is composed of the extracellular matrix, stromal cells, osteoblasts, osteoclasts, and endothelial cells that may produce unique soluble factors, including growth factors and chemotactic factors, to promote $\mathrm{PCa}$ progression in bone.

Chemokines are classified into four major families based upon the relative position of cysteine residues near the NH2-terminus: $\mathrm{CC}, \mathrm{CXC}, \mathrm{C}$, and $\mathrm{CX}_{3} \mathrm{C}$ [Rossi and Zlotnik, 2000]. Chemokines activate receptors, members of large families of seven-transmembrane G-coupled proteins, and play critical roles in cell 
migration during inflammatory responses. In addition, they significantly impact normal development, atherosclerosis, and angiogenesis. Increasing knowledge of the effects of chemokines on different aspects of tumor cell biology, including modulation of proliferation, angiogenesis, and immune response to tumor, has begun to emerge [Strieter, 2001].

Monocyte chemotactic protein-1 (MCP-1) is a member of the $\mathrm{CC}$ chemokine superfamily that plays a critical role in recruitment and activation of monocytes during acute inflammation and angiogenesis [Galasso et al., 2000; Bernardini G et al., 2003; Charo and Taubman, 2004]. A variety of cancer cells that home to bone, including $\mathrm{PCa}$, breast cancer and myeloma cells, express MCP-1 and its receptor CCR2 [Valkovic et al., 1998; Vande Broek et al., 2003; Lu et al., 2006; Mestdagt et al., 2006]. In patients with breast cancer and ovarian cancer, MCP-1 levels are increased in their serum, which correlating with stage of tumors development [Hefler et al., 1999; Lebrecht et al., 2001]. In squamous cell carcinoma of the esophagus, MCP-1 expression in cancer cells is correlated with venous invasion, distant metastasis, and lymph node metastasis [Koide et al., 2004]. Further, our data indicate that MCP-1 is chemotactic for PCa cells [Lu et al., 2006]. In addition, MCP-1 appears to induce proliferation of PCa cells [Lu et al., 2006], osteoclast fusion and osteoclast formation in vitro [Kim et al., 2006]. MCP-1 is also produced by osteoclasts and is upregulated by RANKL and TNF- $\alpha$ in osteoclasts [Graves et al., 1999; Arendt et al., 2002; Park et al., 2005]. Thus, MCP-1, through its receptor CCR2, may play a critical role in tumor development in bone microenvironment.

Chemokine receptors are expressed by a variety of tumor cell types [Dwinell et al., 1999; Scotton et al., 2001; Soejima and Rollins, 2001]. Specifically, CCR2 is expressed in various cancer types including PCa and breast cancers. Certain types of breast cancer and $\mathrm{PCa}$ cell lines also respond to MCP-1 in vitro [Youngs et al., 1997; Lu et al., 2006] indicating presence of functional CCR2 receptors. However, CCR2 expression in different cancer cells and the correlation between CCR2 expression and $\mathrm{PCa}$ progression have not been defined. In this study, we first determined CCR2 mRNA expression in various cancer cell lines including $\mathrm{PCa}$, lung cancer, breast cancer, and myeloma. Further, CCR2 mRNA expression in specimens from PCa patients with bone metastases were examined by analyzing an ONCOMINE gene array database and validated by real-time RTPCR and compared to localized PCa or benign tissues. Finally, CCR2 protein expression was determined by immunohistochemical staining on tissue microarray specimens from $96 \mathrm{PCa}$ patients and 31 benign controls. The correlation between CCR2 expression with Gleason score and clinical pathologic stages was analyzed.

\section{MATERIALS AND METHODS}

\section{Antibodies and Reagents}

Goat anti-human CCR2 polyclonal antibody and isotype control antibody (normal goat IgG) were purchased from Calbiochem (San Diego, CA). The CCR2 antibody is human specific and does not cross react with other chemokine receptors according to the manufacture protocol. The anti-human PSA polyclonal antibody was purchased from Ventana Medical Systems (Tucson, AZ). All chemical reagents were purchased from Sigma (St. Louis, MO).

\section{Cell Culture}

PCa LNCaP, PC3 and DU145 cells, RWPE-1 (non-tumorigenic human prostate epithelial cells), hFOB (SV 40 large T antigen transfected and immortalized human osteoblasts), and HBME (human bone morrow endothelial cells) were obtained from the American Type Culture Collection (ATCC, Rockville, MD). C4-2B cells derived from its parental LNCaP but with characteristics of skeletal metastasis were obtained from UroCor (Oklahoma City, OK). A549, H1299 (human non-small-cell lung carcinoma cell lines), and BEAS2B (non-neoplastic bronchi epithelial cells) were kindly provided by Dr. Xue Wang, at the University of Pittsburgh, Pittsburgh, PA. MDA-MB-231 and MCF-7 (breast cancer cells) were kindly provided by Dr. Shiyuan Cheng, at the University of Pittsburgh. KAS (interleukin-6-responsive myeloma KAS-6/1 cells) were kindly provided by Dr. G. David Roodman, at the University of Pittsburgh. Prostate epithelial cells (PrEC) were purchased from Cambrex (Walkersville, MD). LNCaP, PC3, DU145, H1299, and KAS cells were cultured in RPMI 1640 media (Invitrogen, Carlsbad, CA). The KAS cells were grown in RPMI media supplemented with recombinant human IL-6 (10 ng/ml). Human FOB cells were grown in media with $50 \%$ 
DMEM and 50\% Ham's F12 media (Invitrogen) at $34^{\circ} \mathrm{C}$. At this temperature, the cells exhibit rapid cell division due to the establishment of this cell line by transfection of a temperature sensitive expression vector pUCSVtsA58. C4$2 \mathrm{~B}$ cells were maintained in $\mathrm{T}$ media $[80 \%$ DMEM, 20\% Ham's F12 medium (Invitrogen), $5 \mu \mathrm{g} / \mathrm{ml}$ insulin, $13.6 \mathrm{pg} / \mathrm{ml}$ triiodothyronine, $5 \mu \mathrm{g} / \mathrm{ml}$ transferrin, $0.25 \mu \mathrm{g} / \mathrm{ml}$ biotin, and $25 \mu \mathrm{g} /$ $\mathrm{ml}$ adenine]. HBME, A549, BEAS2B, and MDA-MB231 cells were cultured in DMEM media. MCF-7 cells were cultured in DMEM media supplemented with $5 \mathrm{mg} / \mathrm{ml}$ insulin. All cell cultures were supplemented with $1 \%$ penicillin/streptomycin (Invitrogen) and 10\% FBS (HyClone, Pittsburgh, PA). PrEC were maintained in PrEGM BulletKit media (Cambrex). The RWPE-1 cells were grown in KeratinocyteSerum Free medium supplemented with $5 \mathrm{ng} /$ $\mathrm{ml}$ human recombinant EGF and $0.05 \mathrm{mg} / \mathrm{ml}$ bovine pituitary extract (Invitrogen). All cells, except hFOB, were maintained in $10 \mathrm{~cm}$ tissue culture dishes in a $37^{\circ} \mathrm{C}$ incubator equilibrated with $5 \% \mathrm{CO}_{2}$ in humidified air.

\section{Reverse Transcription-PCR}

Total RNA was extracted from LNCaP, C42B, DU145, PC3, PrEC, RWPE-1, BEAS2B, A549, H1299, MDA-MB-231, MCF-7, KAS, HBME, and hFOB cells; from benign prostate tissue (three cases), localized $\mathrm{PCa}$ (three cases), $\mathrm{PCa}$ with bone-metastases (seven cases), PCa with liver-metastases (two cases), and PCa with lymph node-metastases (two cases) using TRIzol reagent (Life Technologies, Gaithersburg, MD), then subjected to RT-PCR for detection of CCR2 mRNA. Cases of clinically localized PCa were identified from a radical prostatectomy series at the University of Michigan and cases with PCa metastases were obtained from a Rapid Autopsy Program through the Michigan Prostate Specialized Programs of Research Excellence (SPORE) Tissue Core. PCR primers for CCR2 consisted of sense $5^{\prime}$-CTG TCC ACA TCT CGT TCT CGG TTT A-3' and antisense $5^{\prime}-$ CCC AAA GAC CCA CTC ATT TGC AGC-3' resulting in a PCR product of $324 \mathrm{bp}$ [Hanna et al., 2003]. PCR primers for glyceraldehyde-3phosphate dehydrogenase (GAPDH, as control) consisted of sense $5^{\prime}$-CCA TGG AGA AGG CTG GGG-3' and antisense 5'-CAA AGT TGT CAT GGA TGA CC-3' resulting in a PCR product of $194 \mathrm{bp}$ [Park et al., 2002]. RT-PCR was performed with $1 \mu \mathrm{g}$ of total RNA using the
Access RT-PCR system (Promega Corp., Madsion, WI) in a thermal cycler (GeneAmp PCR System 2700, Applied Biosystems, CA) under the following conditions: first strand cDNA was synthesized at $48^{\circ} \mathrm{C}$ for $45 \mathrm{~min}$; then denatured at $94^{\circ} \mathrm{C}$ for $2 \mathrm{~min}$ for the first cycle and at $30 \mathrm{~s}$ for additional 35 cycles; annealing was performed at $55^{\circ} \mathrm{C}$ for $30 \mathrm{~s}$ and extension at $72^{\circ} \mathrm{C}$ for $60 \mathrm{~s}$. Final extension was at $72^{\circ} \mathrm{C}$ for $7 \mathrm{~min}$. The PCR products were subjected to electrophoreses on a $1.5 \%$ agarose gel and stained with ethidium bromide.

\section{Real-Time RT-PCR}

Total RNA was extracted as the same as in RT-PCR. Real-time RT-PCR was performed in an iCycler iQ multicolor real-time PCR detection system (Bio-Rad, Hercules, CA) using iScript one-step RT-PCR kit with SYBR Green (Bio-Rad). Primers for CCR2 were sense 5'-GAC CAG GAA AGA ATG TGA AAG TGA-3', and antisense $5^{\prime}$-GCT CTG CCA ATT GAC TTT CCT T-3' [Johrer et al., 2004]. PCR primers for GAPDH were sense $5^{\prime}$-CCA TGG AGA AGG CTG GGG-3', and antisense 5'-CAA AGT TGT CAT GGA TGA CC-3'. Synthesis of cDNA was performed at $50^{\circ} \mathrm{C}$ for $10 \mathrm{~min}$, then denaturation at $95^{\circ} \mathrm{C}$ for $5 \mathrm{~min}$, followed by 45 cycles with denaturation at $95^{\circ} \mathrm{C}$ for $30 \mathrm{~s}$, annealing at $55^{\circ} \mathrm{C}$ for $15 \mathrm{~s}$, and elongation at $72^{\circ} \mathrm{C}$ for $1 \mathrm{~min}$. The fluorescence intensity of the double-strandspecific SYBR Green, reflecting the amount of formed PCR product, was monitored at the end of each elongation step. Melting curve analysis was performed to confirm the purity of the PCR products. Relative expression of CCR2 was normalized by GAPDH using the $\Delta \mathrm{CT}$ method [relative expression $=2^{-\Delta \mathrm{CT}}$, where $\Delta \mathrm{CT}=\mathrm{C}_{\mathrm{T}(\mathrm{CCR} 2)}-\mathrm{C}_{\mathrm{T}(\mathrm{GAPDH})}$ ] [Wang et al., 2004]. Data are representative of three separate experiments and are presented as the mean \pm SE from triplicates.

\section{Western Blot Analysis}

Cell lysates from LNCaP, C4-2B, DU145, PC3, PrEC, RWPE-1, BEAS2B, A549, H1299, MDA-MB-231, MCF-7, KAS, HBME, and hFOB cells were prepared using standard procedures. All the samples were measured for total protein content using a BCA assay (Pierce, Rockford, IL) to ensure equal loading. Loading buffer was added to $40 \mu \mathrm{g}$ protein and samples were boiled prior to being resolved on $12 \%$ SDS-PAGE gels and then transferred onto PVDF membranes 
(Bio-Rad). The blots were blocked using blocking reagents overnight at $4^{\circ} \mathrm{C}$ with shaking and then incubated for $2 \mathrm{~h}$ with primary antibody for CCR2 (diluted 1:1,000 in blocking solution). The blots were washed and incubated for $1 \mathrm{~h}$ with donkey anti-goat IgG-HRP (1:5,000). After washing, bands were detected using enhanced chemiluminescence (ECL) (Amersham Biosciences, Piscataway, NJ) and exposured to light-sensitive film. As control for equal loading of the proteins, immunoblots for GAPDH (Santa Cruz, CA) were performed on the stripped membranes. CCR2 was normalized to GAPDH, and the fold change was calculated using the mean value of fold changes from three replicates. The data are representative of three separate experiments and are presented as the mean $\pm \mathrm{SE}$ from triplicates.

\section{Microarray Analysis From Meta-Analysis of ONCOMINE Database}

The expression of CCR2 transcript in $\mathrm{PCa}$ tissues was obtained from meta-analysis of cancer gene microarray meta-analysis public database [Rhodes et al., 2004]. Statistical analysis of differences was performed using ONCOMINE algorithms to account for the multiple comparisons among different studies, similar to a meta-analysis, as previously described [Rhodes et al., 2004].

\section{Immunohistochemical Staining and Scoring}

Tissue microarray of $\mathrm{PCa}$ specimens (83 Asian patients who underwent radical prostatectomy with Gleason score 5 and 6: $\mathrm{n}=5$; Gleason score 7: $\mathrm{n}=39$; Gleason score 8: $\mathrm{n}=12$; Gleason score 9 and 10: $\mathrm{n}=27$; Pathological stage pT2: $n=61 ; \mathrm{pT} 3$ and pT4: $\mathrm{n}=22$ ) were purchased from ISU Abxis (Seoul, Korea) with corresponding non-neoplastic tissues (42 specimens); Gift specimens (normal and benign tissues 31 cases and carcinoma 13 cases from American men with Gleason score 5 and $6: \mathrm{n}=6$; Gleason score 7: $\mathrm{n}=2$; Gleason score $8: \mathrm{n}=3$; Gleason score 9 and $10: \mathrm{n}=2$; Pathological stage pT2: $\mathrm{n}=10 ; \mathrm{pT} 3: \mathrm{n}=3$ ) were kindly provided by Cybrdi, Inc. (Frederick, MD). All slides were stained following a modified protocol [VakarLopez et al., 2004]. Briefly, slides were heated at $55^{\circ} \mathrm{C}$ for $30 \mathrm{~min}$, deparaffinized and rehydrated, then antigen retrieval was performed with Target Retrieval kit from Dako (Carpinteria, CA). Slides were incubated for $24 \mathrm{~h}$ at $4^{\circ} \mathrm{C}$ with anti-human CCR2 polyclonal antibody (1:400 dilution), or isotype control goat IgG (1:400 dilution, used as a negative control) or antihuman PSA polyclonal antibody (1:400 dilution, used as a positive control). Biotinylated antigoat or anti-rabbit antibody (Dako) at a dilution of 1:500 was used as the secondary antibody. After incubation in avidin-biotin complex solution (Dako), the staining was developed by the diaminobenzidine method, followed by counterstaining with hematoxylin. Quantitative analysis of the CCR2 expression was determined by scoring protein expression as negative (score $=1)$, weak $($ score $=2)$, moderate (score $=3)$, or strong $($ score $=4)$, which was previously used [Sun et al., 2005]. Differences in CCR2 expression were evaluated statistically using the mean scores from each case. Scoring was performed (by both authors Dr. Jian Zhang at the University of Pittsburgh and Dr. Yulin Liu at the Allegheny General Hospital) without knowledge of overall Gleason score (e.g., tumor grade), tumor size, or clinical outcome [Perrone et al., 2000].

\section{Statistical Analysis}

Statistical analysis was performed using Statview software (Abacus Concepts, Berkley, CA). ANOVA was used for initial analyses, followed by Fisher's protected least significant difference for post hoc analyses. Student's $t$-test was used for analyzing the gene expression data sets from a published cDNA microarray database ONCOMINE [Rhodes et al., 2004]. Differences with a $P<0.05$ were determined to be statistically significant.

\section{RESULTS}

\section{CCR2 Expression in Various Cancer Cells}

To determine whether CCR2 mRNA is differentially expressed by different cancer cell lines, we first tested PCa cell lines LNCaP, C4-2B, PC3, and DU145; lung cancer A549 and H1299; breast cancer MCF-7 and MDA-MB-231; myeloma KAS cells by RT-PCR (Fig. 1A) and then quantified by real-time RT-PCR (Fig. 1B). HBME and hFOB cells were used as a comparison for the cells from bone microenvironment; PrEC and RWPE-1 as a control for PCa, and BEAS2B as a control for lung cancer. All cells expressed CCR2 mRNA, however, CCR2 mRNA expressions in PCa LNCaP, C4-2B, PC3, and DU145 cells were significantly greater when compared to PrEC and RWPE-1 cells 
A

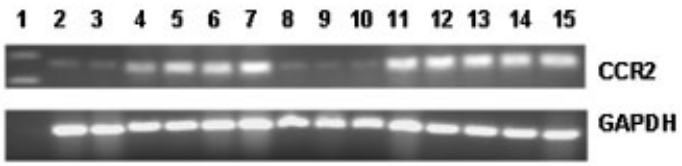

B

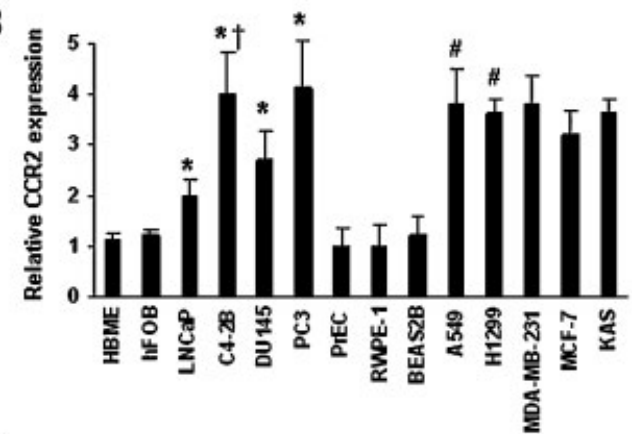

C

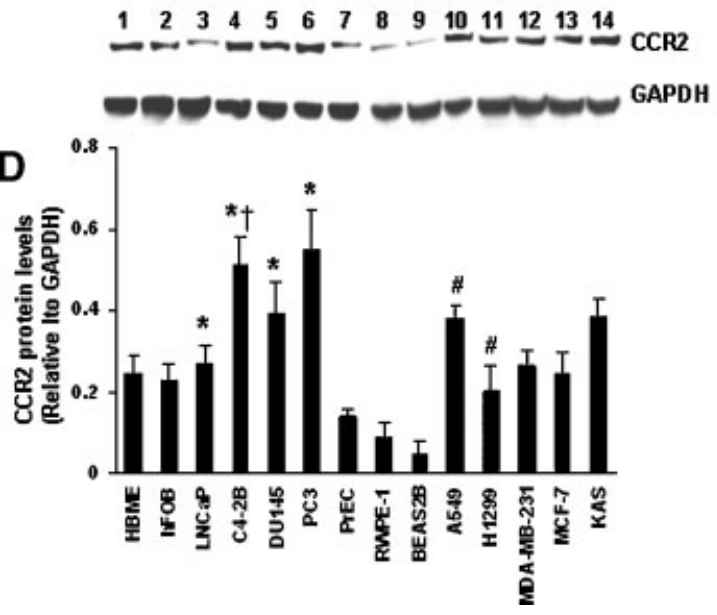

Fig. 1. CCR2 mRNA is highly expressed by aggressive cancer cells. CCR2 mRNA and protein expression in different cell lines were determined by RT-PCR, real-time PCR, and Western blot analysis. A: Total RNA was extracted from the indicated cells and then subjected to RT-PCR. Lane 1: DNA marker; lane 2: HBME; lane 3: $\mathrm{hFOB}$; lane 4: LNCaP; lane 5: C4-2B; lane 6: DU145; lane 7: PC3; lane 8: PrEC; lane 9: RWPE-1; lane 10: BEAS2B; lane 11: A549; lane 12: H1299; lane 13: MDA-MB-231; lane 14: MCF-7; and lane 15: KAS. B: Real time RT-PCR was performed and relative CCR2 mRNA expression was calculated. ${ }^{*} P<0.001$ compared to PrEC or RWPE-1. ${ }^{\dagger} P<0.001$ compared to LNCaP. ${ }^{\#} P<0.001$ compared to BEAS2B. C: Cell lysates were prepared and Western blot analysis was performed. Lane 1: HBME; lane 2: hFOB; lane 3: LNCaP; lane 4: C4-2B; lane 5: DU145; lane 6: PC3; lane 7: PrEC; lane 8: RWPE-1; lane 9:BEAS2B; lane 10: A549; lane 11: H1299; lane 12: MDA-MB-231; lane 13: MCF-7; and lane 14: KAS. D: Quantitative data of Western blot analysis. ${ }^{*} P<0.001$ compared to PrEC or RWPE- $1 .{ }^{\dagger} P<0.001$ compared to LNCaP. ${ }^{\#} P<0.001$ compared to BEAS2B.

(Fig. 1A (lanes 4-9) and Fig. 1B). Specifically, there was about a onefold higher expression observed in $\mathrm{C} 4-2 \mathrm{~B}$ as compared to $\mathrm{LNCaP}$ (Fig. 1A (lanes 4 and 5) and Fig. 1B). CCR2 mRNA expressions in lung cancer A549 and
H1299 cells were significantly greater compared with BEAS2B (Fig. 1A (lanes 11, 12, and 10) and Fig. 1B). Breast cancer, MCF-7 and MDA-MB-231 cells, and myeloma KAS cells expressed similar levels of CCR2 mRNA compared with PCa cells (Fig. 1A (lanes 13-15) and Fig. 1B). HBME and hFOB cells also expressed CCR2 mRNA, but at significantly lower levels (Fig. 1A (lanes 2 and 3) and Fig. 1B).

To determine whether the CCR2 protein expression is also differentially expressed by different cancer cells, CCR2 protein levels in the cell lysates were examined by Western blot analysis (Fig. 1C,D). Consistent with mRNA levels, the more aggressive cancer cells such as C4-2B, PC3, and DU145 expressed higher levels of CCR2 protein compared with the less aggressive cancer cells LNCaP or non-neoplastic PrEC or RWPE-1 cells. CCR2 protein expressions in lung cancer A549 and H1299 cells were significantly higher compared with that in BEAS2B. MCF-7, MDA-MB-231, and KAS expressed similar levels of CCR2 protein compared to $\mathrm{PCa}$ cells, whereas HBME and hFOB expressed low levels of CCR2.

\section{CCR2 mRNA Expression Correlates With PCa Progressiveness}

Analysis of gene expression data sets from cancer gene microarray meta-analysis public database [Rhodes et al., 2004] revealed that CCR2 mRNA expression levels increased with PCa progressiveness (Fig. 2). Yu et al. [2004] originally determined the gene expression patterns in benign prostate tissues (23 cases), localized PCa tissues (64 cases), and metastatic PCa tissues (25 cases). CCR2 mRNA expression was significantly higher in metastatic $\mathrm{PCa}$ compared to both benign prostate tissues $\left(P=4.6 \times 10^{-6}\right)$ and localized PCa $(P=0.002)$. Furthermore, CCR2 mRNA expression was significantly higher in the localized $\mathrm{PCa}$ compared with the benign prostate $(P=0.012)$.

To further confirm the higher expression of CCR2 mRNA in the specimens from metastatic $\mathrm{PCa}$ patients, we extracted total RNA from benign prostate tissues, localized $\mathrm{PCa}, \mathrm{PCa}$ with bone-metastases, $\mathrm{PCa}$ with liver-metastases, and $\mathrm{PCa}$ with lymph node-metastases. Both RT-PCR and real-time RT-PCR analyses were performed on these RNAs (Fig. 3A,B). Specimens from $\mathrm{PCa}$ with metastasis, specifically $\mathrm{PCa}$ with bone-metastases, but not liver-metastases and lymph node-metastases, 


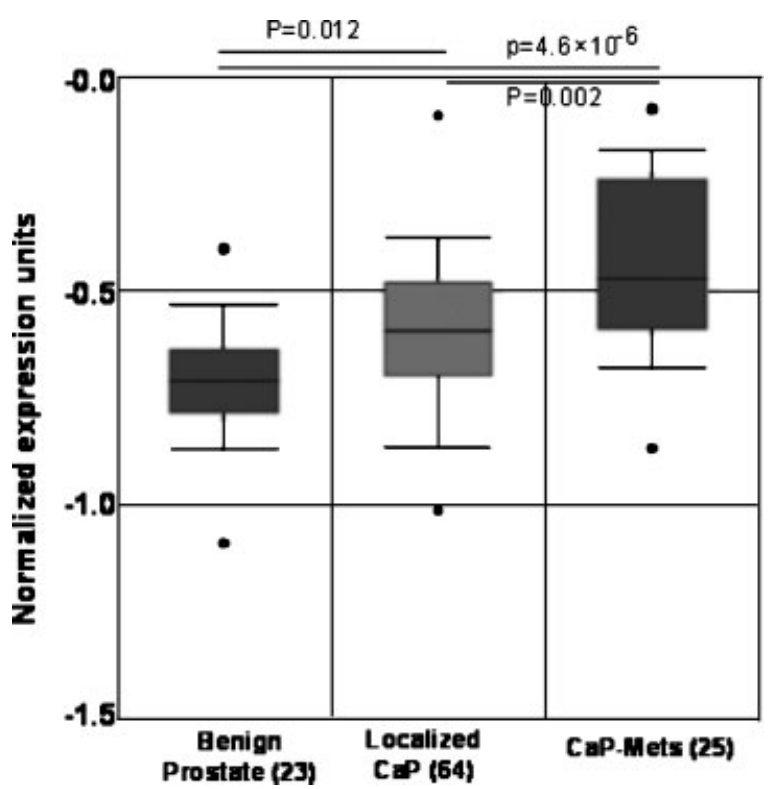

Fig. 2. CCR2 mRNA expression correlates with PCa progressiveness. CCR2 mRNA levels were analyzed by using gene expression data sets from cancer gene microarray meta-analysis public database [Rhodes et al., 2004] that was originally reported by Yu et al. [2004]. Twenty-three cases of benign prostate, 64 cases of localized PCa, and 25 cases of metastatic PCa were included in this study. Y-axis represents normalized expression units. Shaded boxes represent interquartile range making the 25th-75th percentile; whiskers represent 10th-90th percent range; bars represent median. The $P$-value was calculated by using the Student's $t$-test.

expressed significantly higher level of CCR2 mRNA compared to the localized PCa or benign prostate specimens.

\section{CCR2 Protein Expression Correlates With Gleason Score and Pathologic Stages}

To test whether the CCR2 protein is differentially expressed in $\mathrm{PCa}$ tissues compared to benign tissues, immunohistochemical staining was performed on tissue microarray specimens from $96 \mathrm{PCa}$ patients and 31 normal controls. All specimens were graded using the Gleason score system and pathologic stage [Babaian et al., 1995; Gleason and Mellinger, 2002]. The immunohistochemical staining revealed that CCR2 was differentially expressed in $\mathrm{PCa}$ specimens and non-neoplastic tissues (Fig. 4A), and 81 out of 96 (84\%) PCa tissue samples expressed CCR2 at heterogeneous levels. In contrast, 19 out of 73 (26\%) non-neoplastic tissue samples expressed CCR2, although at lower levels. The CCR2 positive staining was located mostly in epithelial and fibromuscular
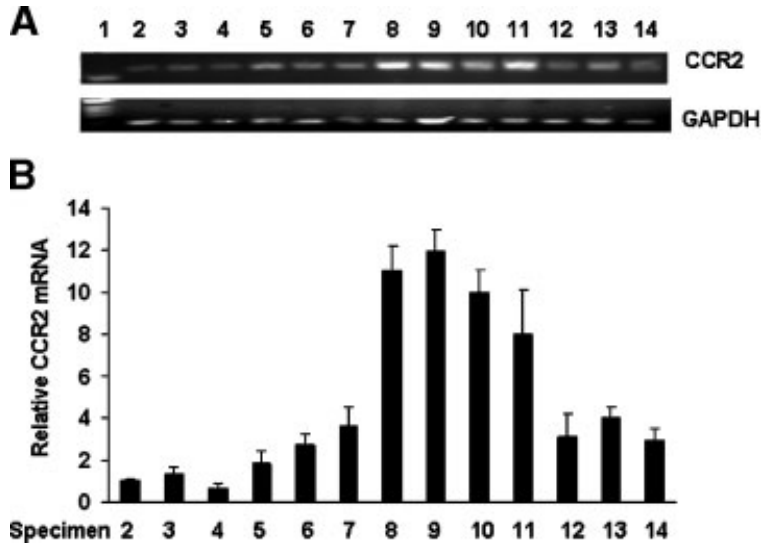

Fig. 3. CCR2 mRNA was highly expressed in metastatic PCa tissues. Total RNA was extracted from benign prostate tissue, localized PCa, PCa with bone-metastases, PCa with livermetastases, and PCa with lymph node-metastases. RT-PCR and real-time RT-PCR were performed. A: PCR products for CCR2 were detected in benign prostate tissues, localized PCa tissues and PCa with metastasis tissues. GAPDH served as an internal control. Lane 1: DNA marker; lanes 2-4: benign prostate tissues; lanes 5-7: Localized PCa; lanes 8-11: PCa bone-metastases; lanes 12-13: PCa liver-metastases; lane 14: PCa lymph nodemetastases. B: Quantitative data for relative mRNA expression (for specimen corresponding to subpart A) by real-time RT-PCR. Data are representative of three separate experiments and is presented as mean \pm SE from triplicates. GAPDH served as an internal control.

stromal cells, but was also noted in some extracellular areas surrounding neoplastic glands and epithelial cells (Fig. 4A). Quantitative analysis showed that levels of CCR2 expression in the malignant epithelia were greater than in the non-neoplastic epithelia, which correlated with Gleason score and pathologic stage (Fig. 4B). Prostate specific antigen (PSA), expressed by prostate epithelium, was immunohistochemically stained and used as a positive control.

\section{DISCUSSION}

Chemokines are produced by various types of human tumors, however, only limited data have been reported on their receptors that mediate the cancer pathobiology. In this study, we first reported that CCR2 mRNA and protein are differentially expressed by various cancer cell lines including $\mathrm{PCa}$, lung cancer, breast cancer, and myeloma. All cells expressed CCR2 mRNA and proteins, however, their expression levels in $\mathrm{PCa}$ cell lines LNCaP, C4-2B, PC3, and DU145 were significantly higher than that of PrEC and RWPE-1. The aggressive cancer cells, 
A
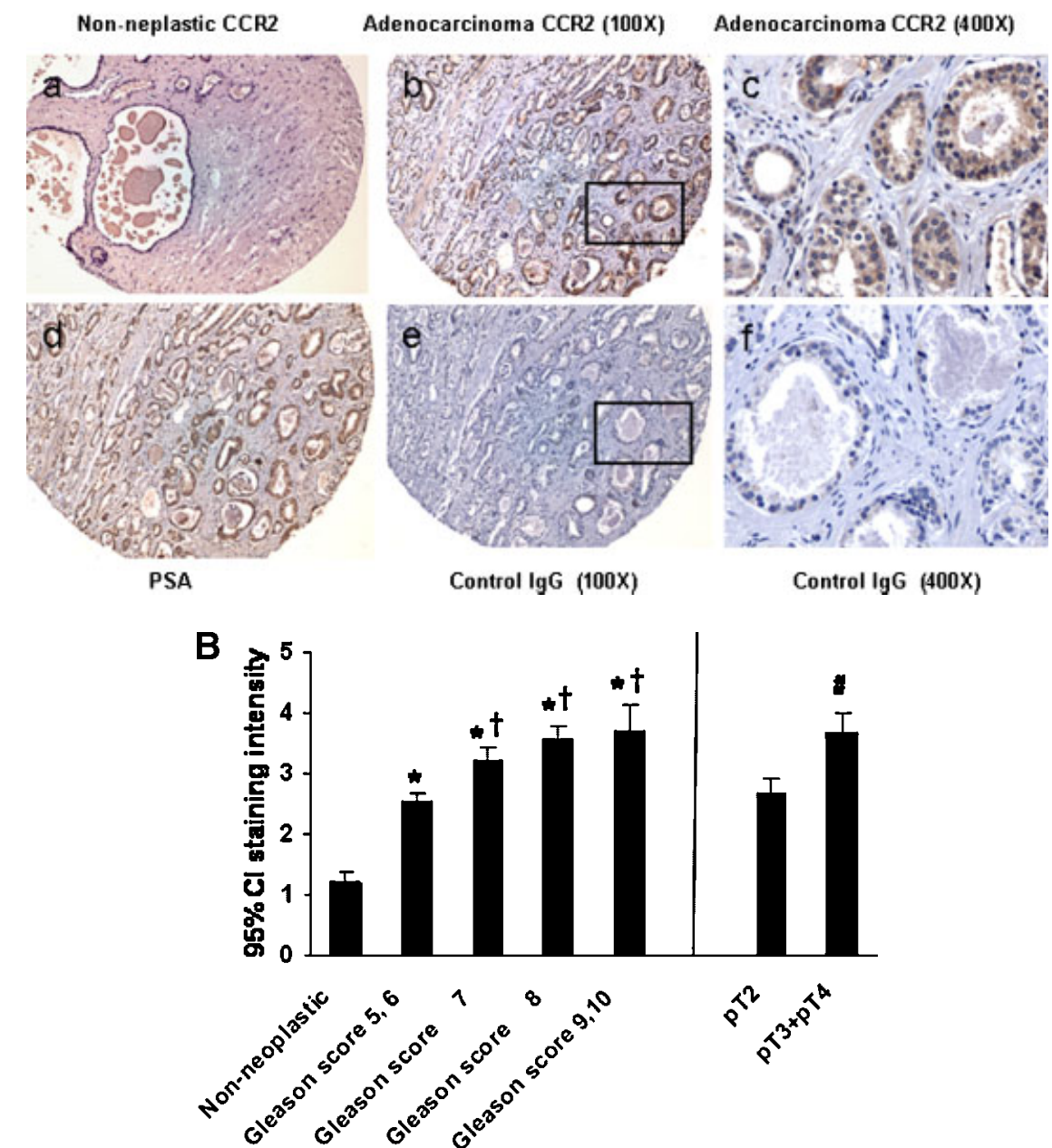

Fig. 4. CCR2 protein expression correlates with Gleason scores and clinical pathologic stages. Immunohistochemical staining was performed for detection of CCR2 in human PCa and non-neoplastic tissues. A: Representatives of staining. a: CCR2 negative staining in non-neoplastic prostate tissue. $\mathbf{b}$ and $\mathbf{c}$ : CCR2 positive staining in PCa tissues. d: PSA positive staining as positive control. $\mathbf{e}$ and $\mathbf{f}$ : Negative staining of CCR2 isotype control lgG antibody. Different sections of b, c, and d are from the same patient. Original magnification: $100 \times$. c and $\mathrm{f}$ magnifica-

both in PCa and lung cancer cell lines, expressed higher levels of CCR2 compared with the less aggressive cancer cells or benign cells.

A positive correlation between CCR2 mRNA expression and $\mathrm{PCa}$ progression was further demonstrated in this study through analyzing an ONCOMINE Gene Array Database. Consistent with the findings on the differential CCR2 mRNA expressions in aggressive cancer cells compared to less aggressive cancer cells, higher mRNA expression in PCa metastatic tissues was validated in bone metastatic tissues tion: $400 \times$. B: Quantitative evaluation of CCR2 expression in PCa. Immunostaining was scored and analyzed as described in Materials and Methods section. The mean expression scores \pm SD for all PCa and non-neoplastic tissues examined cases are presented in a graphical format using error bars with 95\% confidence intervals $(\mathrm{Cl}) .{ }^{*} P<0.001$ compared to non-neoplastic tissues. ${ }^{\dagger} P<0.01$ compared to Gleason score 5 and 6 specimens. ${ }^{\#} P<0.001$ compared to pathological stage T2 specimens.

compared to the localized $\mathrm{PCa}$ or benign prostate tissues by real-time RT-PCR. In addition, the findings that tissues from $\mathrm{PCa}$ with bone-metastases, but not liver-metastases and lymph node-metastases, expressed significantly higher level of CCR2 mRNA compared to the localized PCa or benign prostate tissues, which suggest that CCR2 may be one of the bone specific mediators that plays a critical role in the crosstalk between PCa cells and the bone microenvironment. Although we were unable to distinguish exactly what cell type(s) might 
overexpress CCR2 transcripts in the metastatic tissues, the fact that CCR2 is differentially expressed in both PCa cell lines and tissues led us to examine its expression in situ on $\mathrm{PCa}$ specimens. Thus, we examined the CCR2 protein expressions using immunohistochemical staining in specimens from $\mathrm{PCa}$ patients and normal control tissues. CCR2 expressions correlated with Gleason score as well as clinical pathologic stages, while lower levels of CCR2 were expressed in normal prostate tissues. CCR2 positive stainings were located mostly in epithelial, fibromuscular stromal cells, and in the extracellular areas surrounding neoplastic glands and epithelial cells. These positive stainings suggested that CCR2 was overexpressed not only in PrECs, but also in the bone microenvironment. To cover broader specimens, we included specimens from both Asian and American men in this study. These results suggested that CCR2 contributes to PCa progression.

Chemokines regulate metastatic behavior of cancer cells through their functional receptors. It has been reported, for example, the chemokine stromal-derived factor (SDF-1; CXCL12) and its receptor CXCR4 play important role in various tumor cells, including PCa [Aiuti et al., 1999; Kim and Broxmeyer, 1999] cells, homing to bone. Tumor cells that frequently metastasize to bone (myeloma, breast cancer, $\mathrm{PCa}$, and neuroblastoma) all express CXCR4 [DarashYahana et al., 2004; Gazitt and Akay, 2004]. However, blocking CXCR4 only partially inhibits bone metastasis [Marchesi et al., 2004]. These data indicate that other factors, produced by cancer cells or cells in the bone microenvironment, may also contribute to the pathogenesis of cancer bone metastases. Those factors may attract and stimulate cancer cell growth in bone.

Recent studies have shown that the expression of CC chemokine CCL5 (RANTES) is important in the progression of breast cancer [Manes et al., 2003]. A chemokine receptor antagonist of CCR5 (one of the CCL5 receptors) inhibited experimental breast tumor growth [Robinson et al., 2003]. Vaday et al. [2006] recently demonstrated that PCa cells expressed functional CCR5 receptors that may mediate pro-malignant activities. Together with our findings, in this study, it is shown that CCR2 is highly expressed by metastatic or aggressive $\mathrm{PCa}$ cells compared to less aggressive cancer cells, and chemokines and chemokines receptors, including MCP-1/CCR2, may have profound effects on tumor progression. Although there is no published data on testing a conceivable hypothesis that CCR2 blockage may prevent tumor growth in vivo, there is evidence that MCP-1 deficient mice may be protected in models of endogenous mammary carcinoma development [Conti and Rollins, 2004], which supports and promotes researchers to pursue further studies in vivo.

When PCa cells metastasize to bone, they interact with the bone microenvironment. These interactions result in growth of PCa cells and osteolysis followed by osteoblastic response. There are bidirectional interactions between $\mathrm{PCa}$ cells and the bone microenvironment that increase production and expression of unique cytokines/chemokines and adhesion molecules on both marrow stromal cells and PCa cells, which drive the bone destruction process. Among the factors, we have demonstrated in this study that CCR2, the functional receptor for MCP-1, may mediate PCa development in bone. Although further studies are needed to delineate the factors regulating CCR2 expression in PCa cells and bone cells, our data from this study suggest that CCR2 may be a novel therapeutic target for PCa treatment.

\section{ACKNOWLEDGMENTS}

We gratefully acknowledge Dr. G. David Roodman and Dr. Deborah L. Galson for their helpful discussions and Ms. Jana Clever for her editing.

\section{REFERENCES}

Abrams HL, Spiro R, Goldstein N. 1950. Metastases in carcinoma; analysis of 1000 autopsied cases. Cancer 3:74-85.

Aiuti A, Tavian M, Cipponi A, Ficara F, Zappone E, Hoxie J, Peault B, Bordignon C. 1999. Expression of CXCR4, the receptor for stromal cell-derived factor-1 on fetal and adult human lympho-hematopoietic progenitors. Eur J Immunol 29:1823-1831.

Arendt BK, Velazquez-Dones A, Tschumper RC, Howell KG, Ansell SM, Witzig TE, Jelinek DF. 2002. Interleukin 6 induces monocyte chemoattractant protein-1 expression in myeloma cells. Leukemia 16:2142-2147.

Babaian RJ, Troncoso P, Steelhammer LC, Lloreta-Trull J, Ramirez EI. 1995. Tumor volume and prostate specific antigen: Implications for early detection and defining a window of curability. J Urol 154:1808-1812.

Bernardini G RD, Spinetti G, Morbidelli L, Ziche M, Santoni A, Capogrossi MC, Napolitano M. 2003. Analysis 
of the role of chemokines in angiogenesis. J Immunol Methods 273:83-101.

Bubendorf L, Schopfer A, Wagner U, Sauter G, Moch H, Willi N, Gasser TC, Mihatsch MJ. 2000. Metastatic patterns of prostate cancer: An autopsy study of 1,589 patients. Hum Pathol 31:578-583.

Charo IF, Taubman MB. 2004. Chemokines in the pathogenesis of vascular disease. Circ Res 95:858-866.

Coleman RE. 1997. Skeletal complications of malignancy. Cancer 80:1588-1594.

Conti I, Rollins BJ. 2004. CCL2 (monocyte chemoattractant protein-1) and cancer. Semin Cancer Biol 14:149-154.

Darash-Yahana M, Pikarsky E, Abramovitch R, Zeira E, Pal B, Karplus R, Beider K, Avniel S, Kasem S, Galun E, Peled A. 2004. Role of high expression levels of CXCR4 in tumor growth, vascularization, and metastasis. Faseb J 18:1240-1242.

Dwinell MB, Eckmann L, Leopard JD, Varki NM, Kagnoff MF. 1999. Chemokine receptor expression by human intestinal epithelial cells. Gastroenterology 117:359367.

Galasso JM, Stegman LD, Blaivas M, Harrison JK, Ross BD, Silverstein FS. 2000. Experimental gliosarcoma induces chemokine receptor expression in rat brain. Exp Neurol 161:85-95.

Gazitt Y, Akay C. 2004. Mobilization of myeloma cells involves SDF-1/CXCR4 signaling and downregulation of VLA-4. Stem Cells 22:65-73.

Gleason DF, Mellinger GT. 2002. Prediction of prognosis for prostatic adenocarcinoma by combined histological grading and clinical staging. 1974. J Urol 167:953-958; discussion 959

Graves DT, Jiang Y, Valente AJ. 1999. The expression of monocyte chemoattractant protein-1 and other chemokines by osteoblasts. Front Biosci 4:D571-580.

Hanna J, Wald O, Goldman-Wohl D, Prus D, Markel G, Gazit R, Katz G, Haimov-Kochman R, Fujii N, Yagel S, Peled A, Mandelboim O. 2003. CXCL12 expression by invasive trophoblasts induces the specific migration of CD16- human natural killer cells. Blood 102:15691577.

Hefler L, Tempfer C, Heinze G, Mayerhofer K, Breitenecker G, Leodolter S, Reinthaller A, Kainz C. 1999. Monocyte chemoattractant protein-1 serum levels in ovarian cancer patients. Br J Cancer 81:855-859.

Johrer K, Janke K, Krugmann J, Fiegl M, Greil R. 2004. Transendothelial migration of myeloma cells is increased by tumor necrosis factor (TNF)-alpha via TNF receptor 2 and autocrine up-regulation of MCP-1. Clin Cancer Res 10:1901-1910.

Kim CH, Broxmeyer HE. 1999. SLC/exodus2/6Ckine/TCA4 induces chemotaxis of hematopoietic progenitor cells: Differential activity of ligands of CCR7, CXCR3, or CXCR4 in chemotaxis vs. suppression of progenitor proliferation. J Leukoc Biol 66:455-461.

Kim MS, Day CJ, Selinger CI, Magno CL, Stephens SR, Morrison NA. 2006. MCP-1-induced human osteoclastlike cells are tartrate-resistant acid phosphatase, NFATc1, and calcitonin receptor-positive but require receptor activator of NFkappaB ligand for bone resorption. J Biol Chem 281:1274-1285.

Koide N, Nishio A, Sato T, Sugiyama A, Miyagawa S. 2004. Significance of macrophage chemoattractant protein-1 expression and macrophage infiltration in squamous cell carcinoma of the esophagus. Am J Gastroenterol 99: 1667-1674

Landis SH, Murray T, Bolden S, Wingo PA. 1999. Cancer statistics. CA Cancer J Clin 49:8-31, 31.

Lebrecht A, Hefler L, Tempfer C, Koelbl H. 2001. Serum cytokine concentrations in patients with cervical cancer: Interleukin-4, interferon-gamma, and monocyte chemoattractant protein-1. Gynecol Oncol 83:170171.

Lu Y, Cai Z, Galson DL, Xiao G, Liu Y, George DE, Melhem MF, Yao Z, Zhang J. 2006. Monocyte chemotactic protein1 (MCP-1) acts as a paracrine and autocrine factor for prostate cancer growth and invasion. Prostate 66:13111318.

Manes S, Mira E, Colomer R, Montero S, Real LM, GomezMouton C, Jimenez-Baranda S, Garzon A, Lacalle RA Harshman K, Ruiz A, Martinez AC. 2003. CCR5 expression influences the progression of human breast cancer in a p53-dependent manner. J Exp Med 198:1381-1389.

Marchesi F, Monti P, Leone BE, Zerbi A, Vecchi A, Piemonti L, Mantovani A, Allavena P. 2004. Increased survival, proliferation, and migration in metastatic human pancreatic tumor cells expressing functional CXCR4. Cancer Res 64:8420-8427.

Mestdagt M, Polette M, Buttice G, Noel A, Ueda A, Foidart JM, Gilles C. 2006. Transactivation of MCP-1/CCL2 by beta-catenin/TCF-4 in human breast cancer cells. Int J Cancer 118:35-42.

Moul JW, Lipo DR. 1999. Prostate cancer in the late 1990s: Hormone refractory disease options. Urol Nurs 19:125131; quiz 132-133.

Park JH, Park BH, Kim HK, Park TS, Baek HS. 2002. Hypoxia decreases Runx2/Cbfa1 expression in human osteoblast-like cells. Mol Cell Endocrinol 192:197-203.

Park HJ, Park OJ, Shin J. 2005. Receptor activator of NFkappaB ligand enhances the activity of macrophages as antigen presenting cells. Exp Mol Med 37:524-532.

Perrone EE, Theoharis C, Mucci NR, Hayasaka S, Taylor JM, Cooney KA, Rubin MA. 2000. Tissue microarray assessment of prostate cancer tumor proliferation in African-American and white men. J Natl Cancer Inst 92:937-939

Rana A, Chisholm GD, Khan M, Sekharjit SS, Merrick MV, Elton RA. 1993. Patterns of bone metastasis and their prognostic significance in patients with carcinoma of the prostate. Br J Urol 72:933-936.

Rhodes DR, Yu J, Shanker K, Deshpande N, Varambally R, Ghosh D, Barrette T, Pandey A, Chinnaiyan AM. 2004. ONCOMINE: A cancer microarray database and integrated data-mining platform. Neoplasia 6:1-6.

Robinson SC, Scott KA, Wilson JL, Thompson RG, Proudfoot AE, Balkwill FR. 2003. A chemokine receptor antagonist inhibits experimental breast tumor growth. Cancer Res 63:8360-8365.

Rossi D, Zlotnik A. 2000. The biology of chemokines and their receptors. Annu Rev Immunol 18:217-242.

Scotton C, Milliken D, Wilson J, Raju S, Balkwill F. 2001. Analysis of CC chemokine and chemokine receptor expression in solid ovarian tumours. $\mathrm{Br} \mathrm{J}$ Cancer 85:891-897.

Soejima K, Rollins BJ. 2001. A functional IFN-gammainducible protein-10/CXCL10-specific receptor expressed by epithelial and endothelial cells that is neither CXCR3 nor glycosaminoglycan. J Immunol 167:6576-6582. 
Strieter RM. 2001. Chemokines: Not just leukocyte chemoattractants in the promotion of cancer. Nat Immunol 2:285-286.

Sun YX, Schneider A, Jung Y, Wang J, Dai J, Wang J, Cook K, Osman NI, Koh-Paige AJ, Shim H, Pienta KJ, Keller ET, McCauley LK, Taichman RS. 2005. Skeletal localization and neutralization of the SDF-1(CXCL12)/CXCR4 axis blocks prostate cancer metastasis and growth in osseous sites in vivo. J Bone Miner Res 20:318-329.

Vaday GG, Peehl DM, Kadam PA, Lawrence DM. 2006. Expression of CCL5 (RANTES) and CCR5 in prostate cancer. Prostate 66:124-134.

Vakar-Lopez F, Cheng CJ, Kim J, Shi GG, Troncoso P, Tu SM, Yu-Lee LY, Lin SH. 2004. Up-regulation of MDABF-1, a secreted isoform of ErbB3, in metastatic prostate cancer cells and activated osteoblasts in bone marrow. J Pathol 203:688-695.

Valkovic T, Lucin K, Krstulja M, Dobi-Babic R, Jonjic N. 1998. Expression of monocyte chemotactic protein-1 in human invasive ductal breast cancer. Pathol Res Pract 194:335-340.
Vande Broek I, Asosingh K, Vanderkerken K, Straetmans N, Van Camp B, Van Riet I. 2003. Chemokine receptor CCR2 is expressed by human multiple myeloma cells and mediates migration to bone marrow stromal cell-produced monocyte chemotactic proteins MCP-1,-2 and -3. Br J Cancer 88:855-862.

Wang J, Xi L, Hunt JL, Gooding W, Whiteside TL, Chen Z, Godfrey TE, Ferris RL. 2004. Expression pattern of chemokine receptor 6 (CCR6) and CCR7 in squamous cell carcinoma of the head and neck identifies a novel metastatic phenotype. Cancer Res 64:18611866.

Youngs SJ, Ali SA, Taub DD, Rees RC. 1997. Chemokines induce migrational responses in human breast carcinoma cell lines. Int J Cancer 71:257-266.

Yu YP, Landsittel D, Jing L, Nelson J, Ren B, Liu L, McDonald C, Thomas R, Dhir R, Finkelstein S, Michalopoulos G, Becich M, Luo JH. 2004. Gene expression alterations in prostate cancer predicting tumor aggression and preceding development of malignancy. J Clin Oncol 22:2790-2799. 